\title{
ANÁLISE DA NARRATIVA DE VIKTOR FRANKL ACERCA DA EXPERIÊNCIA DOS PRISIONEIROS NOS CAMPOS DE CONCENTRAÇÃO
}

\author{
Analysis of Viktor Frankl's Narrative on the Experience of Prisoners in Concentration Camps \\ Análisis de la Narrativa de Viktor Frankl sobre la Experiencia de los Presos en Campos \\ de Concentración
}

Thiago Antonio Avellar de Aquino

\begin{abstract}
Resumo: O objetivo do presente artigo foi identificar a estrutura lexical mais significativa na obra de Viktor Frankl Em busca de sentido: um psicólogo no campo de concentração. O corpus do texto foi analisado por meio do software ALCESTE (Análise Lexical Contextual de um Conjunto de Segmentos de Texto), um método computacional que se propõe a decompor um texto a fim de obter as estruturas mais significativas. Os significados encontrados foram divididos em três classes subdivididas em dois eixos: Facticidade e Posicionamento Psicoexistencial dos Prisioneiros. Por meio dessa análise foi possível identificar as palavras mais características utilizadas por Frankl na sua narrativa acerca da vivência do prisioneiro no campo de concentração. Os resultados foram discutidos com base nos direitos humanos e na logoterapia e análise existencial.
\end{abstract}

Palavras-chave: Existencialismo; Prisioneiros; Historicidade; Léxico.

Abstract: The aim of this paper was to identify the lexical structure more significant in the work of Viktor Frankl's Man's Search for Meaning. The text corpus was analyzed by the software ALCESTE (Lexical analysis by context of a set of text segments), a computational method that aims to decompose a text in order to obtain the most significant structures. The meanings found were divided into three classes subdivided into two axes: Facticity and Psycho-existential Positioning of Prisoners. By this analysis it was possible to identify the most typical words used by Frankl in his narrative about the experience of the prisoner in a concentration camp. The results were discussed based on human rights and logotherapy and existential analysis.

Keywords: Existentialism; Prisoners; Historicity; Lexicon.

Resumen: El objetivo de este trabajo fue identificar la estructura léxica más importante en la labor de búsqueda de Viktor Frankl en busca de sentido: un psicólogo en el campo de concentración. La recopilación del texto fue analizado por el software ALCESTE (Análisis léxico por el contexto de un conjunto de segmentos de texto), un método computacional que tiene como objetivo descomponer un texto con el fin de obtener las estructuras más importantes. Los significados que se encuentran divididos en tres categorías, subdivididas en dos ejes: facticidad y posicionamiento psico-existencial de los reclusos. Mediante este análisis se pudo identificar las palabras más típicas utilizadas por Frankl en su relato sobre la experiencia de los prisioneros en un campo de concentración. Los resultados fueron discutidos con base en los derechos humanos y en la logoterapia y análisis existencial.

Palabras-clave: Existencialismo; Reclusos; Historicidad; Lexico.

\begin{abstract}
"Nossa geração é realista porque chegamos a conhecer o ser humano como ele de fato é. Afinal, ele é aquele ser que inventou as câmaras de gás de Auschwitz; mas ele é também aquele ser que entrou naquelas câmaras de gás de cabeça erguida, tendo nos lábios o Pai Nosso ou o Shemá Yisrael"
\end{abstract}

(Frankl, 2010)

\section{Introdução}

Viktor Frankl (1905-1997) é considerado como o fundador da Logoterapia e Análise Existencial, abordagem psicoterápica desenvolvida em Viena, posterior à Psicanálise de Freud e à Psicologia Individual de Adler
(Lukas, 1989). Por um lado, trata da busca de significado para a vida como motivador primário do ser humano; por outro, as possibilidades de decaimento psíquico por ocasião da frustração existencial. Sua teoria foi constituída na primeira metade do século XX, com sólidas bases filosóficas e mediante as experiências clínicas com jovem em situação de risco (Frankl, 2006). Mas, inequivocamente, suas ideias foram corroboradas com suas vivências como prisioneiro comum em quatro campos de concentração nazistas durante a Segunda Guerra Mundial.

Após a sua soltura, Frankl ditou em nove dias o livro Ein Psycholog erlebt das Konzentrationslage ("Um psicólogo no campo de concentração"), que trata da sua vivência como prisioneiro comum, sob o número 119.104, e da des- 
crição dos aspectos psicológicos e existenciais dos demais encarcerados. Esse livro foi considerado por Karl Jaspers como "um dos poucos grandes livros da humanidade" (Garcia Pintos, 2007). Gordon Allport, por ocasião do prefácio da edição americana do referido livro, concebe que “(...) é uma obra-prima de narrativa dramática focalizada nos mais profundos problemas humanos” (Frankl, 2010).

Já Caldas e Calheiros (2012), tecendo comentários sobre esse autor, afirmam que:

sua experiência como prisioneiro de campos de concentração serviria, assim, para comprovar que o ser humano é portador - além das dimensões física e psíquica -, de uma dimensão mais abrangente que pode dotá-lo de uma surpreendente força de resistência (p. 93).

Dessa forma, considerando a relevância desse livro no âmbito da psicologia humanista-existencial, o objetivo do presente artigo foi o de realizar uma análise lexical com o intuito de identificar as estruturas mais significativas desse texto. Antes de apresentar o material, que foi objeto de análise, torna-se relevante tecer alguns comentários acerca de alguns aspectos teóricos desenvolvidos pelo autor em foco, o que será apresentado no tópico que se segue.

\section{Logoterapia e Análise Existencial}

A Logoterapia é definida como uma psicoterapia centrada no sentido da existência, já que a palavra grega logos corresponde a sentido e direção e therapeía deriva-se do verbo therapeúo, prestar cuidados médicos, tratar (Liddell \& Scott, 1983). Dessa forma, constitui-se em uma forma de tratar por meio do sentido. Essa primeira acepção refere-se a um sistema de cura, mas de forma geral sua fundamentação constitui-se de três eixos básicos: a liberdade da vontade, a vontade de sentido e o sentido da vida (Lukas, 1989). A liberdade da vontade constitui o eixo antropológico, que pressupõe uma liberdade de escolha apesar dos condicionamentos externos e internos. Dessa maneira, o ser humano não seria livre dos condicionamentos, mas em última instância poderia decidir o que irá ser no próximo instante (Frankl, 1978, 1989a, 1989b).

O segundo eixo corresponde à vontade de sentido. Segundo essa concepção teórica, o ser humano seria motivado por um desejo de configurar sentidos e valores em sua existência, isto é, em todas as suas experiências no mundo. Para Frankl (1989a, 2010), essa motivação se constitui como um fenômeno primário e como o principal fator de proteção da saúde mental. Por fim, o terceiro eixo é aquele que corresponde ao sentido da vida, ou seja, a visão filosófica do mundo. Para essa perspectiva, ao contrário da visão niilista, na vida há sempre um sentido a ser desvelado, latente nas situações, e nessa busca a consciência intuitiva (Gewissen) seria o órgão que rastreia as possibilidades de sentido.

A outra característica da teoria de Frankl (1989a, 1990) é a análise existencial, que se constitui como um método antropológico de pesquisa. Segundo o autor, não há nenhuma explicação ou síntese da existência, já que “(...) a pessoa também se explica a si mesma: se explica, se desdobra se desenvolve no transcurso da vida" (Frankl, 1990, p. 63). Dessa maneira, o próprio ser humano em última instância lê na vida, ou seja, explica-se a si mesmo, sendo o papel da análise existencial compreender a existência em suas possibilidades de ser no mundo bem como em seus desdobramentos.

Destarte, a logoterapia como uma modalidade de análise existencial pode ser classificada como uma Geisteswissenschaft, ou seja, uma ciência do espírito (Dilthey, 1989), por esse motivo preocupa-se com os fenômenos especificamente humanos. Nesse sentido, em sua ontologia dimensional, atém-se em compreender quem é o homem, advogando que o ser humano é muito mais do que a sua dimensão psicofísica, constituído também por uma dimensão dos fenômenos especificamente humanos, denominada de noológica. Essa dimensão define a sua verdadeira humanidade, correspondendo à preocupação com valores (a ética e a estética), os atos intencionais, a criatividade, o humor, o senso religioso, a preocupação com o sentido e todos os atos que diferenciam os homens dos animais (Lukas, 1989).

Frankl (1989a) compreende que o principal fenômeno humano é a vontade de configurar um sentido para a vida, que se constitui como um desejo de realizar valores durante a sua existência finita e limitada no tempo e no espaço, tornando-se responsável por algo ou alguém. Destarte, esse autor apregoa que o ser humano quando frustrado na sua busca de sentido, pode ocorrer uma sensação de vazio existencial, resultante da carência de valores existenciais. Essa sensação constitui-se como uma neurose coletiva nas sociedades industriais, por esse motivo, o homem atual necessita extrair sentido na sua relação com o mundo, posto que não receberia mais os valores por meio da tradição.

Para a logoterapia o homem comum, por meio de sua “autocompreensão ontológica pré-reflexiva”, concebe três vias de encontro de sentido na vida: os valores vivenciais, criativos e atitudinais. O primeiro é caracterizado como as vivências com a natureza e/ou com um tu, o segundo é a qualidade de criar algo para o mundo, como uma obra artística ou científica e está, em geral, relacionado com a capacidade de trabalhar. $\mathrm{O}$ terceiro vincula-se à postura perante uma situação imutável, ou seja, aquela característica humana de transformar um sofrimento em uma realização ou conquista, que geralmente está associada com a capacidade de suportar o sofrimento inevitável (Frankl, 1989a).

Para esse autor o mundo é constituído por valores, sendo esses considerados como objetos dignos de inten- 
cionalidade, ou seja, os valores transcendem a própria esfera do ser humano. Por esse motivo, "a logoterapia se baseia em afirmações sobre valores tomados como fatos, não em julgamentos sobre fatos tomados como valores" (Frankl, 2011, p. 92). Nessa perspectiva, a realização dos valores decorre da concepção de que a pessoa é um ente aberto para o mundo, que é sempre um ser em relação a algo. A essa capacidade de sair de sua própria esfera para se lançar para o mundo, Frankl denominou de autotranscendência, ou seja, aquela capacidade de voltar-se para algo ou alguém além de si mesmo (Frankl, 1989a, 1978).

Outra característica antropológica é o autodistanciamento que se constitui como uma capacidade humana de se afastar dos condicionamentos internos ou externos. Segundo o próprio autor, "as autênticas faculdades humanas ancestrais da autotranscendência e do autodistânciamento, tal como afirmo nos últimos anos, foram verificadas e convalidadas de forma existencial no campo de concentração" (Frankl, 2006, p. 86).

Frankl (2010) considera que suas concepções foram validadas de forma vivencial durante a Segunda Guerra Mundial. Para tanto, utiliza-se da perspectiva fenomenológica a qual define da seguinte maneira:

a fenomenologia é uma tentativa de descrição do modo como o ser humano entende a si próprio, do modo como ele próprio interpreta a própria existência, longe de padrões preconcebidos de explicação, tais como os forjados no seio das hipóteses psicodinâmicas ou socioeconômicas (Frankl, 2011, p. 16).

Destarte, o relato sobre suas vivências como prisioneiro nos campos de concentração constitui uma forma de validação existencial das suas próprias concepções acerca do ser humano. Torna-se pertinente nesse momento apresentar, de forma sucinta, o conteúdo do seu manuscrito autobiográfico, o que será descrito a seguir.

\section{O Campo de Concentração}

Viktor Frankl, por ser de origem judaica, foi deportado para o gueto de Theresienstadt junto com a sua família (os pais e sua esposa). Esse local era considerado a porta de entrada para os campos de extermínio e nele permaneceu durante vinte e cinco meses até ser transferido, em outubro de 1944, para Auschwitz-Birkenau na Polônia onde recebeu o número 119.104. O lema desse campo era: Arbeit macht frei, o trabalho liberta (Herrera, 2007), o que não se constituía apenas como uma medida disciplinar, mas como uma tortura psicológica. Outros campos nos quais esse autor esteve interno foram as dependências de Dachau: Kaufering e Turkhein, onde permaneceu até o dia 27 de abril de 1945, quando foi libertado por ocasião do término da guerra (Garcia Pintos, 2007).
Pode-se constatar que a narrativa de Viktor Frankl (2010) decorre da sua vivência nos campos de Auschwitz, Dachau e Theresienstadt como prisioneiro comum, já que o mesmo foi torturado e sobreviveu à custa do trabalho forçado em escavações e construções de ferrovias. O autor, em sua narrativa, propõe-se a responder à seguinte questão: "de que modo se refletia na mente do prisioneiro a vida cotidiana no campo de concentração?" (Frankl, 2010, p. 15). Dessa forma, objetivou compreender as atitudes dos cárceres mediante os fatos que causaram uma experiência psicológica (Frankl, 2010).

Por ocasião da sua reclusão e por meio de uma autoobservação e da observação dos seus companheiros de reclusão, pôde identificar três fases distintas pelas quais os internos estruturaram suas experiências: Choque de entrada, fase de adaptação e fase da soltura (Frankl, 1990, 2010). A primeira fase, o choque da entrada, se caracteriza pelo contato intersubjetivo dos prisioneiros novatos com os antigos bem como com os guardas e os comandantes do campo. A recepção não é amistosa e logo os prisioneiros abandonam possíveis ilusões, que no caso de Frankl seria o de conservar um manuscrito científico. Decorre daí que o prisioneiro muda de sua situação existencial pregressa para se deparar com uma perspectiva caracterizada como "sem saída”, próximo da sua morte e da morte de outros companheiros. Entretanto, nesse estágio o prisioneiro não teme a morte e a câmara de gás, tornando o suicídio um ato desnecessário.

Enquanto a primeira fase é caracterizada pelo pânico, a segunda é marcada pela indiferença. Na fase de adaptação, o prisioneiro se torna apático, os sentimentos tornam-se embutidos, como um mecanismo de defesa daquela situação de extremo sofrimento. Por essa razão, não chegam a manifestar emoções tais como amarguras, indignações e desesperanças.

Nesta fase de adaptação, a vida afetiva vai se reduzindo e a aspiração primordial é a sobrevivência, regredindo à vida instintiva mais primitiva. Além da apatia, o prisioneiro é acometido por uma irritabilidade expressa por certo nível de agressão, o que Frankl (2010) atribui não apenas a uma origem psicológica, mas também à ausência de cafeína e nicotina. Mediante a situação sociológica em que se encontravam, não era incomum o sentimento de inferioridade nos prisioneiros comuns, aqueles que não tinham privilégios.

Embora tenham regredido ao estágio da luta pela sobrevivência, duas áreas de interesse se sobressaíam: a política e a religião. A primeira temática está vinculada à esperança do fim da guerra, que nem sempre era verossímil; já a segunda surpreendia os prisioneiros recémchegados pela vitalidade das preces e orações em lugares improvisados.

Gradativamente os internos progrediam para um tipo de experiência da existência provisória, pois "o fato de que não exista um término da forma de existir no campo de concentração conduz à experiência de um futuro ine- 
xistente" (Frankl, 1990, p. 207). Ocorre, portanto, uma perda da estrutura temporal, levando o prisioneiro a uma experiência de um futuro inexistente, o que, por conseguinte, o conduz a viver no imediatismo.

Herrera (2007), ao comentar o relato de Frankl, resume em três aspectos a vida anímica do prisioneiro:

1. A vida onírica, como expressão das aspirações e desejos dos presos;

2. O silêncio do impulso e desejo sexual;

3. A depreciação de tudo aquilo que não serve para conservar a vida, que se expressou na falta, quase absoluta, de sentimentalidade ou falta de reação emotiva (p. 43).

Para o recluso que perde a noção dos fins e de uma meta em sua existência, sucumbe à própria apatia, ou seja, não se preocupam mais com a higiene e com a alimentação, recusando-se a encarar o trabalho forçado e suportando com indiferença o castigo imposto. Sobre isso Frankl (1990) observa que:

(...) A orientação a um 'fim' e a uma meta posta no futuro representa aquele apoio espiritual que tanto necessita o detento no campo de concentração, porque apenas esse apoio espiritual é capaz de preservar o homem para que não caia em mãos dos poderes do entorno social que imprimem caráter e que formam tipos, ou seja, para que não se deixe cair (p. 208).

Frankl (2010) observa que em última instância o prisioneiro decidia que tipo de pessoa gostaria de se tornar, um recluso típico ou tomar uma postura alternativa. A essa atitude espiritual denominou de força de obstinação do espírito. $\mathrm{O}$ autor narra exemplos de prisioneiros que conseguiram, apesar da irritabilidade e apatia, uma superação das condições internas e externas e passavam pelos barracões proferindo algumas palavras de conforto e oferecendo um pedaço de pão. Nesses casos, pode-se afirmar que alguns dos prisioneiros ainda permaneceram humanos apesar das condições desumanas, embora esse fato tenha ocorrido de forma escassa. Entretanto, para aqueles que conseguiram se posicionar com uma atitude livre, os campos lhes proporcionaram uma progressão moral e religiosa (Frankl, 1990). Para esse tipo de prisioneiro "nunca tinha considerado a vida no campo de concentração como um mero episódio - para eles era mais, e se converteu, no auge de sua existência" (Frankl, 1990, pp. 211-212).

Por fim a terceira fase foi o da soltura, nela os prisioneiros ainda estão tomados pelo sentimento de despersonalização e tudo lhes parece um sonho, um simulacro de liberdade. Eles passam de um estado de tensão elevada para o de distensão, ou seja, ocorre uma descompressão repentina, o que seria prejudicial para a saúde mental (Frankl, 2010). Dois sentimentos atormentam os recém- libertos: a amargura e a decepção. Quando retornam para os antigos ambientes, as pessoas, de forma geral, reagem de maneira vaga ou superficial com relação ao sofrimento que tinham vivenciado, o que leva o sobrevivente ao seguinte questionamento: "para que serviu tanto sofrimento?”. Já a decepção estava relacionada à sensação de desamparo quando não mais encontra o ente querido que tanto esperava reencontrar quando estava nos campos de concentração e que lhe dava esperanças, como expressou o ex-recluso: "Ai daquele em quem não existe mais a razão de suas forças no campo de concentração" (Frankl, 2010, p. 118). Torna-se fundamental um acompanhamento psicoterápico para os ex-detentos.

Tendo em vista a narrativa do prisioneiro 119.104, torna-se relevante analisar essa obra de uma forma mais detalhada, tanto para a compreensão da experiência dos prisioneiros do campo de concentração, como para a compreensão dos aspectos teóricos da logoterapia e análise existencial. Sendo assim, o objetivo do presente trabalho foi identificar os campos lexicais ou contextos semânticos que organizam a narrativa de Viktor Frankl acerca de suas vivências e análises do prisioneiro nos Campos de Concentração Nazistas.

\section{Método}

\subsection{Material}

O corpus analisado foi a primeira parte do livro Em busca de sentido: um psicólogo no campo de concentração, extraído da vigésima nona edição da versão em português editado pela Sinodal e Vozes. Esse manuscrito foi produzido por Viktor Frankl após a guerra, além de se constituir como uma narrativa autobiográfica que descreve a psicologia do prisioneiro nos campos de concentração por ocasião da Segunda Guerra Mundial. Para efetuar a análise do corpus, este foi transcrito para um documento do Word for windows e salvo no formato texto-txt.

\subsection{Procedimentos}

Com o objetivo de realizar uma análise de dados textuais do corpus escolhido, foi utilizado o programa computacional ALCESTE (Analyse de lexémes coocurrent dans les ennoncés simples d'un texte), versão 4.7, que se constitui como uma via para uma análise textual, identificando as classes de palavras emergentes de um discurso (Reinert, 1990). Dentre outras finalidades, esse programa se presta também a analisar obras literárias em seus contextos semânticos. Para tanto, parte-se do princípio de que as pessoas se expressam por meio de um universo lexical que representa suas estruturas mentais.

De forma específica, o programa agrupa as palavras por radicais calculando a sua frequência no corpus do texto para, em seguida, prover as unidades de contex- 
to elementares (UCE). Dessa forma, "é a partir do pertencimento das palavras de um texto a uma UCE, que o programa ALCESTE vai estabelecer as matrizes a partir das quais será efetuado o trabalho de classificação" (Reinert, 1998, p. 17). Para tanto, o programa utiliza-se do cálculo do qui-quadrado para identificar tanto os vocábulos mais característicos que compõem uma classe com a força de associação entre as palavras e a classe. Nesse sentido, foi realizada uma classificação hierárquica descendente.

\subsection{Resultados}

Segundo Kronberger e Wagner (2002), a análise com ALCESTE tem por objetivo distinguir classes de palavras que representam diferentes formas de pensar acerca de uma temática específica. No caso da presente pesquisa, a temática foi a narrativa de Viktor Frankl acerca da experiência dos prisioneiros nos campos de concentração. A análise dos resultados foi obtida por meio do corpus de uma unidade de contexto inicial (UCI), constituída pela vivência de Frankl descrita no livro Em busca de sentido. Quando processado pelo software ALCESTE apresentou uma divisão do corpus em 2101 unidades de contexto elementar (UCE) contendo 8989 palavras, formas ou vocábulos distintos e 74\% das UCE foram analisadas, o que se considera satisfatório visto que a solução aceitável requer no mínimo 70\% (Kronberguer \& Wagner, 2002). O ALCESTE organizou as ideias mais relevantes da obra analisada em três classes, dispostas em dois eixos principais.

A Figura 1 apresenta o Dendograma que representa as classes que emergiram após a análise lexical. Ele proporciona a visualização, de forma decrescente, das palavras mais significativas em função das classes, que são concebidas como contextos semânticos. Tendo em vista que a força de associação entre o vocábulo e a classe é representada por meio do cálculo do qui-quadrado, consideraram-se apenas as palavras que apresentaram $\chi^{2} \geq 3,84(p=0,05)$.

\begin{tabular}{|c|c|c|}
\hline \multicolumn{3}{|c|}{$\begin{array}{l}\text { Classe } 1 \text { : } \\
\text { Cotidiano dos Prisioneiros } \\
1360 \text { u.c.e. }=64,7 \% \text { do total } \\
\text { Palavras de maior associação: }\end{array}$} \\
\hline Palavras: & Freq. & $x$ \\
\hline Barract & 57 & 27,0 \\
\hline Trabalhot & 55 & 25,9 \\
\hline Companheirot & 56 & 26.5 \\
\hline $\mathrm{Dia}+$ & 67 & 22.4 \\
\hline Os & 141 & 17.8 \\
\hline Transp ort+ & 33 & 15,8 \\
\hline Campot & 94 & 13.2 \\
\hline Entrt & 27 & 12,5 \\
\hline Frente+ & 33 & 11.6 \\
\hline Auschwitz & 21 & 11,6 \\
\hline Ao & 95 & 10,7 \\
\hline Medt & 31 & 10.6 \\
\hline Meit & 20 & 11,0 \\
\hline $\mathrm{Cam+}$ & 20 & 11,0 \\
\hline Noit+ & 28 & 10.9 \\
\hline Lado+ & 18 & 9,9 \\
\hline Chefet & 18 & 9.9 \\
\hline $\mathrm{Mao+}$ & 16 & 8,8 \\
\hline Chegt & 31 & 8.8 \\
\hline Caminht & 20 & 8,7 \\
\hline Repouso & 16 & 8,7 \\
\hline Pequent & 17 & 9.3 \\
\hline Păo & 14 & 7.7 \\
\hline frit & 14 & 7.7 \\
\hline
\end{tabular}

Facticidade dos p rision eiros

\begin{tabular}{|c|c|c|}
\hline \multicolumn{3}{|c|}{$\begin{array}{l}\text { Classe 2: } \\
\text { Atitude Singular do prisioneir o } \\
497 \text { u.c.e. }=23,7 \% \text { do total } \\
\text { P alavras de } m \text { aior as sociaça: }\end{array}$} \\
\hline Palavras: & Freq. & $x^{2}$ \\
\hline Sofrit & 31 & 96.5 \\
\hline Sent+ & 33 & 89,6 \\
\hline Pessot & 74 & 88,1 \\
\hline Exist+ & 35 & 84,5 \\
\hline Vida & 61 & 72.6 \\
\hline Futuro & 15 & 43,9 \\
\hline Interiort & 27 & 43,4 \\
\hline Hum ana+ & 16 & 35,6 \\
\hline Situact & 21 & 31.7 \\
\hline Possibilidade+ & 9 & 29,2 \\
\hline $\mathrm{Diz}+$ & 16 & 27,2 \\
\hline Disst & 14 & 26,6 \\
\hline Ser hum ano & 11 & 26,9 \\
\hline Experit & 18 & 24,3 \\
\hline Pergunt+ & 18 & 24,0 \\
\hline Liberdade & 13 & 23,7 \\
\hline Arte & 7 & 22,7 \\
\hline Caráter & 7 & 22,7 \\
\hline Conquist+ & 7 & 22,7 \\
\hline Pensamento+ & 7 & 22,7 \\
\hline Alvo & 8 & 21,3 \\
\hline Espiritu+ & 9 & 20,7 \\
\hline Podt & 35 & 18,6 \\
\hline Fat+ & 15 & 18,5 \\
\hline
\end{tabular}

\begin{tabular}{|c|c|c|}
\hline \multicolumn{3}{|c|}{$\begin{array}{l}\text { Classe } 3: \\
\text { Reaçőes } \mathrm{P} \text { sicológicas } \\
244 \text { u.c.e. }=11,6 \% \text { do total } \\
\text { Palavras de maior associação: }\end{array}$} \\
\hline Palavias: & Freg & $x$ \\
\hline Psicologt & 26 & 169.7 \\
\hline Anim + & 17 & 87,9 \\
\hline React & 12 & 68.8 \\
\hline Caust & 12 & 58,1 \\
\hline $\mathrm{Tip}+$ & 12 & 53,6 \\
\hline Fase & 8 & 52,6 \\
\hline Apat+ & 10 & 49,1 \\
\hline Manifest + & 6 & 45.8 \\
\hline Prisioneirot & 27 & 39.7 \\
\hline Psiqu+ & 5 & 38.1 \\
\hline Primitivt & 9 & 38 \\
\hline Perigost & 4 & 30,5 \\
\hline Irritabilidade & 4 & 30,5 \\
\hline Instinto+ & 5 & 30.1 \\
\hline Fisiológicat & 5 & 30,2 \\
\hline Circunstanciat & 5 & 30,1 \\
\hline $\begin{array}{l}\text { Campo de } \\
\text { concentraçäo }\end{array}$ & 24 & 28,1 \\
\hline Aliment+ & 6 & 26.7 \\
\hline Choque & & 24.5 \\
\hline Sentìt & 9 & 23.9 \\
\hline Explict & 5 & 24,5 \\
\hline Falt+ & 6 & 22,9 \\
\hline Condict & 6 & 22.9 \\
\hline Higien+ & 3 & 22,9 \\
\hline
\end{tabular}

Posicionamento psico-existencial dos Prisioneiros

Figura 1. Dendograma com Classificação Hierárquica Descendente 
Como se pode observar, o primeiro eixo é composto por $64,4 \%$ do conteúdo analisado e está relacionado com a facticidade dos prisioneiros no campo de concentração, ou seja, as condições em que os prisioneiros se encontravam imersos e sem a participação da vontade dos mesmos. A classe 1, que compõe esse eixo, foi composta por palavras e radicais no intervalo de $\chi^{2}=27$ [barrac+(barraca, barracão, barracas, barracões)] a $\chi^{2}=7,7$ [pão; fri+(fria, frieza, frio)]. Pode-se atribuir a essa classe a denominação de destino, o que se constitui por condições externas e internas as quais não são passíveis de escolha por parte do prisioneiro. A seguir são apresentadas algumas UCE representativas dessa classe:

(...) cansaço, o prato de sopa na mão, quando entrou um companheiro correndo (...) aconteceu? A passos lentos os companheiros se arrastam em direção ao (...) repente saio do barracão rumo à enfermaria para avisar o meu colega (...) frente ao pequeno fogão do barracão, cuidando do fogo naquelas horas (...) parar meu colega e amigo P. ele foi mandado para o outro lado? Sim (...) dia seguinte o capo me contrabandeou para outro comando de trabalho (...) fui acordado pelo companheiro que dormia ao meu lado a gemer e (...) amontoavam cerca de cinquenta companheiros com febre alta, delirantes (...) galpão a me mandar para a enfermaria central a fim de receber (...) enfermos. Os destinados para o transporte, aqueles corpos consumidos (...) tentaria arranjar algum pedaço de pão para comermos nos dias seguintes (...) dois doentes de tifo exantemático, dois enfermeiros, um medico. E já (...) pedaço de pão no bolso da capa, com os dedos desprovidos de luvas e (...) no chão, enquanto os demais eram forçados a ficar de pá horas a fio (...) uma voz de comando: grupo de trabalho weingut, marchar! esquerda, 2 (...) gola da capa o companheiro que marcha ao meu lado murmura de repente (...) quem trabalhei lado a lado, por semanas a fio, no local da construção (...) solta sua língua, e começa a contar coisas, horas e horas a fio (...) campos menores, sentados, acocorados ou de pé, no chão de terra (...)

Já o segundo eixo foi composto por duas classes, que concentraram $35,3 \%$ do conteúdo, referindo-se ao posicionamento psico-existencial dos prisioneiros. Na classe 2 predomina a referência às reações e posicionamentos dos prisioneiros e abarcou palavras no intervalo de $\chi^{2}=96,5$ [sofri+(sofrimento, sofrimentos)] a $\chi^{2}=18,5$ [fat+(fatais, fatal, fato, fator)]; já a classe 3 agrupa ideias sobre as reações psíquicas dos mesmos. Essa última abrange os vocábulos de $\chi^{2}=169,7$ [psicolog+(psicologia, psicológica, psicológicas, psicológico, psicológicos, psicólogo)] a $\chi^{2}=$ 22,9 [higien+ (higiene, higiênicas); condic+(condição, condições)]. Para ilustrar o contexto do discurso referente à classe 2, são apresentados os seguintes fragmentos do texto analisado:
(...) justamente uma situação exterior extremamente difícil que da à pessoa (...) somente uma vida ativa tem sentido, em dando a pessoa a oportunidade (...) uma chance de se realizar criativamente e em termos de experiência (...) falando em termos filosóficos, se poderia dizer que se trata de fazer (...) uma única resposta correta à pergunta contida na situação concreta (...) gozo da vida, que permite à pessoa a realização na experiência do que (...) caracteriza cada pessoa humana e dá sentido à existência do individuo (...) entorpece em semelhante situação interior e exterior? para não falar (...) espiritual dotado de liberdade interior e valor pessoal. Ela (...) concentração se pode privar a pessoa de tudo, menos da liberdade não se pode perder. Sem duvida, elas poderiam dizer que foram dignas (...) e belo, na experiência da arte ou da natureza. Também há sentido (...) como testemunho para o fato de que a pessoa interiormente pode ser (...) existência também não consegue viver em função de um alvo. ela também (...) esquecidas as possibilidades de influência criativa sobre a realidade (...) que ele somente pode existir propriamente com uma perspectiva futura (...) exigência, e com ela o sentido da existência, altera-se de pessoa para (...) cumprir uma tarefa. Havia muito sofrimento esperando ser resgatado por (...) concentração foram de natureza individual e coletiva. As tentativas (...)

Por sua vez a classe 3, Reações Psicológicas, pode ser ilustrada por meio dos seguintes extratos do texto de Viktor Frankl:

(...) importa na medida em que tem um número de prisioneiro, representando (...) novo a alegrar-se. Sob o ponto de vista psicológico, pode-se chamar de (...) segunda fase dentro das reações anímicas do recluso no (...) terceira fase de reações anímicas do recluso, ou seja, a psicologia de (...) natural e, conforme ainda se mostrara, típica naquelas circunstancias (...) necessidades mais primitivas fá-lo experimentar a satisfação das (...) campo de concentração naturalmente apresentava muitos aspectos (...) seja, de enfrentar decisões. A apatia tem ainda outras causas e não (...) psicológica e explicação psicopatológica dos traços típicos com que a (...) sobre a capacidade de resistência dos prisioneiros se manifestou (...) apatia dos outros, e mais ainda diante do perigo em que ela coloca a (...) queremos detalhar a seguir. A observação psicológica dos reclusos, no (...) ex-prisioneiro 119104 tenta descrever agora o que vivenciou como (...) nós, prisioneiros, já atingíramos este ponto no curso dos eventos (...) segundo estágio de suas reações psíquicas, não mais tenta ignorar a (...) quantidades de calorias. O alivio psíquico e produzido por ilusões que (...) preponderância dos instintos primitivos e a peremptória necessidade de (...) aquilo que não serve a este interesse exclusivo. Assim se explica 


\section{a (...) das circunstâncias e a despeito de sua delicada sensibilidade (...)}

Em síntese, da análise da estrutura lexical da narrativa de Frankl emergiram dois polos: por um lado, a condição cotidiana que se configurou como o destino, e, por outro, as reações psíquicas e a mobilização da dimensão noológica dos prisioneiros.

\section{Discussão}

Viktor Frankl reconhece que a sua descrição como um observador participante poderia ter o viés subjetivo por se tratar de uma experiência pessoal (Frankl, 2010). Por esse motivo, faz a seguinte consideração: “(...) deixarei que outros destilem mais uma vez o que está sendo apresentado, tirando do estrato dessas experiências subjetivas suas conclusões impessoais em forma de teorias objetivas" (Frankl, 2010, p. 21). Seguindo essa recomendação, realizou-se uma análise textual do seu relato autobiográfico. Considerou-se que o objetivo foi atingido tendo em vista que, por meio de uma análise lexical, encontrou-se uma estrutura da narrativa desse autor.

Diferentemente de outros autores como Levi (1990), que se preocuparam em descrever os horrores dos campos de concentração, Frankl coloca os acontecimentos nos campos como o pano de fundo para compreender o vivido dos cárceres, posto que o seu foco foi a experiência psicológica dos prisioneiros comuns. Para tanto, o autor utiliza-se de um método que supera a dualidade sujeito-objeto, ou seja, é o de um observador participante utilizando-se de uma postura fenomenológica ao analisar o vivido de sua própria consciência. Cabe agora analisar os eixos e as classes que emergiram; o que será desenvolvido a seguir.

\section{Eixo I - Facticidade dos prisioneiros}

O eixo I foi composto por uma classe, a qual se constituiu como o maior poder explicativo desse dendograma (64,7\% do total). As palavras de maior associação dessa classe referem-se ao destino sociológico dos prisioneiros, ou seja, o contexto ambiental que não é passível de mudança. A estrutura revela-se de forma coerente com a proposta do narrador do texto, em suas próprias palavras ele faz a seguinte consideração: "apresentaremos os fatos apenas na medida em que eles desencadeavam uma experiência na própria pessoa (...)" (Frankl, 2010, p. 19). Os "fatos" representam no dendograma o primeiro eixo, ou seja, o cotidiano, que se associou com o segundo eixo Posicionamento Psicoexistencial dos Prisioneiros. Frankl (1989a) considerou que em última instância a liberdade seria a escolha das potencialidades do vir-a-ser, como por exemplo, uma atitude pessoal perante a conjuntura de condicionamentos. Assim, haveria duas possibilidades de posicionar-se perante a facticidade do campo de concentração, uma é a de ser um prisioneiro típico e a outra é a de tomar uma atitude livre perante as condições impostas.

Embora a Declaração Universal dos Direitos Humanos (ONU, 1948) tenha sido proclamada posterior à Segunda Guerra, considera-se pertinente analisar o primeiro eixo da estrutura léxica, Facticidade dos Prisioneiros, a ótica dos artigos mais violados durante a permanência dos reclusos nos campos de concentração. Por exemplo, o Artigo I reza que "Todas as pessoas nascem livres e iguais em dignidade e direitos. São dotadas de razão e consciência e devem agir em relação umas às outras com espírito de fraternidade". O direito à liberdade foi cerceado tendo em vista que os prisioneiros se encontravam destituídos de escolha e se consideravam joguetes do próprio destino.

Já o Artigo II prescreve que

Toda pessoa tem capacidade para gozar os direitos e as liberdades estabelecidos nesta Declaração, sem distinção de qualquer espécie, seja de raça, cor, sexo, língua, religião, opinião política ou de outra natureza, origem nacional ou social, riqueza, nascimento, ou qualquer outra condição.

No campo de concentração as pessoas eram julgadas de acordo com a sua raça. A esse respeito Frankl (2010) concebeu que existem apenas duas raças, a das pessoas decentes e a das indecentes, independente do grupo em que as pessoas se encontrem. Apesar da perseguição étnico-religiosa os prisioneiros puderam expressar o sentimento religioso em lugares improvisados:

O interesse religioso dos prisioneiros, na medida em que surgia, era o mais ardente que se possa imaginar. Não era sem um certo abalo que os prisioneiros recém-chegados se surpreendiam pela vitalidade e profundidade do sentimento religioso. O mais impressionante neste sentido devem ter sido as reações aos cultos improvisados, no canto de algum barracão ou num vagão de gado escuro e fechado, no qual éramos trazidos de volta após o trabalho em uma obra mais distante, cansados, famintos e passando frio em nossos trapos molhados (Frankl, 2010, p. 51).

No Artigo III reza que "Toda pessoa tem direito à vida, à liberdade e à segurança pessoal." Os prisioneiros que não serviam mais para o trabalho não tiveram direito a uma vida digna, sendo encaminhados para a câmara de gás aqueles que não estavam aptos ao trabalho. Frankl (1989a) apregoa a dignidade e o valor incondicional da pessoa humana e não os condicionam a sua capacidade de produzir para a sociedade. O próprio Frankl (2006), por ocasião da autorização da eutanásia em pacientes psicóticos, alterou os laudos médicos com a intenção de salvar seus pacientes quando ainda podia atuar no Hospital Judeu. 
No que se refere ao Artigo IV, "Ninguém será mantido em escravidão ou servidão, a escravidão e o tráfico de escravos serão proibidos em todas as suas formas", os prisioneiros foram tratados como escravos, já que eram obrigados a trabalhos forçados a fim de sobreviverem, restritos a uma alimentação com poucas calorias. Por fim, no Artigo V encontra-se escrito que "Ninguém será submetido à tortura, nem a tratamento ou castigo cruel, desumano ou degradante". Segundo o relato de Frankl (2010), ao chegar ao campo os prisioneiros tinham todos os pertences subtraídos, raspado todo pelo do corpo e chicoteados sem nenhuma razão.

Frankl (1990) compreendeu em sua análise existencial que o ser humano não é livre de condições. $\mathrm{O}$ autor em foco considera que o ser humano não está no vácuo, mas se encontra sempre em relação a algo que o condiciona. De fato, o homem como ser-no-mundo está enraizado na existência, sempre está em relação a algo ou alguém. Entretanto, a forma de se relacionar com o mundo no campo de concentração foi desumanizante, pois os prisioneiros eram tratados como coisas. O Eixo I, de forma geral, enfatiza a vivência cotidiana do prisioneiro comum ao ser inserido em um processo de despersonalização. Apesar da perda da sensibilidade, os prisioneiros ainda se indignavam com as injustiças acometidas sem nenhuma razão, o que remete ao segundo eixo.

\section{Eixo II - Posicionamento psicoexistencial}

Esse eixo é composto por duas classes: atitude singular dos prisioneiros e reações psicológicas. Enquanto a segunda classe explicou $23,7 \%$ do total, a terceira apresentou o menor poder explicativo do dendograma (11,6\% do total). Percebe-se que na classe 2 predominaram conteúdos concernentes à dimensão noológica, enquanto na classe 3 prevaleceram as palavras que referenciam o estado anímico dos prisioneiros. Frankl (2010) destaca, por um lado, algumas características psíquicas, tais como a perda da sensibilidade (embotamento afetivo), a irritabilidade e o sentimento de inferioridade do prisioneiro. Além da apatia, foi observado também o temor em tomar decisões, pois as consequências poderiam ser imprevisíveis.

Por outro lado, o referido autor concebeu que há uma estranha relação dialética entre existência e facticidade, advogando que são “(...) dois momentos que se interdependem e se exigem reciprocamente. Estão sempre incrustados um no outro, razão pela qual só a força é que se pode separá-los" (Frankl, 1990, p. 96). Essa perspectiva corroborada por meio do significado do termo Ex-sistir, ou seja, sair de si mesmo e confrontar-se (Frankl, 1990).

Para comprender a narrativa de Frankl, torna-se necessário compreendê-la no conjunto de sua obra científica. Destarte, pode-se considerar que esse manuscrito seja complementar ao livro que Frankl publica em 1946: Ärztliche Seelsorge, cura médica de almas, o qual estava escrevendo antes da sua internação nos campos e tentou reconstruí-lo no final da guerra quando contraiu tifo exantemático. Nesse livro, o autor trata das grandes temáticas de sua análise existencial, dentre elas a do sofrimento humano e as possíveis posturas perante a sua facticidade.

A narrativa de Frankl sobre os campos de concentração torna-se uma validação dos pressupostos filosóficos da logoterapia onde demonstra a capacidade do espírito humano em resistir ao sofrimento quando se depara com uma situação limite. Nessa perspectiva, Frankl (1989a) conclui que sofrimento destituído de sentido pode levar ao desespero. Destarte, o papel do médico e também do psicoterapeuta seria aquele de consolar o homo patiens, ou seja, seguir o imperativo colocado no portal do Hospital Geral de Viena por seu fundador, o imperador José II: "salus et solatio aegrorum", ou seja, "não só a cura, mas também a consolação dos doentes" (Frankl, 1990).

Nesse sentido, o projeto fundante da análise existencial desse autor foi o de reumanizar a medicina e a psicoterapia, pois quando o profissional tornar-se um técnico, perde de vista o caráter especificamente humano do seu paciente. Dessa maneira, o psicólogo deveria confrontar a capacidade do paciente de se posicionar perante o seu psicofísico (facticidade), instância na qual a pessoa não pode eleger ou realizar escolhas. Isso significa que quando o ser humano se encontra com um sofrimento inevitável, pode escolher uma atitude perante a sua própria dor, encontrando um sentido por meio dos "valores atitudinais" (Frankl, 1990).

Para tanto, o autor em foco acentua a capacidade prospectiva do ser humano no campo de concentração, pois a experiência de três anos em Auschwitz e Dachau lhe ensinou que o mais relevante para a sobrevivência naquela situação era estar orientado para o futuro, para uma pessoa a ser encontrada ou um sentido a realizar após a guerra (Frankl, 1989b). Nessa perspectiva, o segundo eixo da análise apresentou uma associação entre as reações psíquicas e a atitude singular do prisioneiro.

Frankl (1989b) apresenta o seguinte exemplo do que ocorrera no gueto de Theresienstadt:

Foi publicada uma lista de com o nome dos cerca de mil jovens que na manhã seguinte seriam retirados do gueto. Quando amanheceu o dia, era do conhecimento geral que a livraria do gueto fora esvaziada. Cada um daqueles rapazes - que estavam condenados a morrer no campo de concentração de Auschwitz - pegara um par de livros do poeta, do romancista ou pensador preferido e o escondera na mochila (p. 27).

Nesse sentido, demonstra a capacidade dos prisioneiros de se posicionarem perante as suas últimas áreas de liberdade até o encontro com a morte. Em outros momentos, os prisioneiros expressaram os valores vivenciais quando contemplam o pôr do sol ou uma música do violino (Frankl, 2010). Nessa perspectiva, a análise semântica das palavras que se associaram em 
torno da classe 2 sugere as posturas e atitudes singulares dos prisioneiros, o que se torna possível mediante a força de resistência do espírito humano. Sobre isso comenta Frankl (1989b): “as pessoas acentuavam suas diferenças individuais. Vinha à luz a natureza animal do homem, mas acontecia o mesmo para a santidade. A fome era a mesma, mas as pessoas eram diferentes" (p. 42). Herrera (2007) salienta que essa liberdade interior do prisioneiro não era uma liberdade-de (livre dos condicionamentos), mas uma liberdade-para (tomada de posição apesar dos condicionamentos). Destarte, ao descrever a existência desnuda dos prisioneiros, segundo a narrativa do autor, pôde-se contatar que eles não eram apenas um joguete do próprio destino, mas que foi possível naquela situação tomar uma postura pessoal perante o psicofísico do prisioneiro, o que na análise se constituiu como a classe 2 .

\section{Considerações Finais}

O objetivo do presente artigo foi identificar a estrutura lexical mais significativa do livro Em busca de sentido: um psicólogo no campo de concentração, o que foi considerado plenamente alcançado. No entanto, faz-se necessário nesse momento elencar algumas limitações do estudo. Inicialmente considera-se que a análise foi feita por meio de uma tradução do alemão para o português. Assim, questiona-se se o significado semântico pode ter sido modificado ou mesmo que a tradução tenha sido um viés no presente estudo. Dessa forma, recomenda-se fortemente que outros estudos, ao utilizarem dessa mesma metodologia, possam se ater ao texto original em sua versão germânica.

Outra questão a ser ressaltada é que o autor da narrativa tanto foi observador quanto objeto de observação, já que o mesmo não poderia se distanciar do contexto em que estava inserido. Considera-se que ele foi um observador participante, narrando também as próprias vivências no campo. Entretanto, sabe-se que ele já vinha desenvolvendo a sua perspectiva teórica antes de ingressar como recluso nos campos de concentração. Dessa forma, a sua visão de homem e de mundo poderia ter facilitado na constatação dos fenômenos especificamente humanos. Embora tenha feito uma análise fenomenológica da vivência do prisioneiro, não é possível saber até que ponto ele suspendeu o seu olhar teórico para realizar tal observação. Nesse caso, sugere-se que outros manuscritos, de outros autores que passaram por essa mesma experiência, possam ser analisados para efeito de comparação com a descrição de Viktor Frankl.

Sobre a intenção de escrever o seu relato sobre a sua vivência nos campos, o próprio autor esclarece que "havia querido simplesmente transmitir ao leitor, através de um exemplo concreto, que a vida tem um sentido potencial sob quaisquer circunstâncias, mesmo as mais miseráveis"
(Frankl, 2010, p. 10). Nesse sentido a obra poderia ter um efeito terapêutico ou biblioterapêutico sobre o leitor, entretanto não se conhecia até então a estrutura lexical que estaria latente ao manuscrito que pudesse mobilizar os recursos internos da pessoa humana.

Outro ponto relevante da sua narrativa refere-se a questões éticas acerca das posturas das pessoas que sofrem injustiça. Apesar dos relatos dos pequenos atos heróicos dos prisioneiros, Frankl (1989b) considera que os 'homens humanos' se constituem como minoria. Para esse autor, o prisioneiro que tomou uma postura ética ou humana, diante dos condicionamentos impostos nos campos, o fez de forma facultativa. A esse respeito ele tece o seguinte argumento: "contudo é exatamente esse fato que deve estimular a cada um de nós a unir-se à minoria: as coisas vão mal, mas se não fizermos o melhor que pudermos para fazê-las progredir, tudo será ainda pior" (Frankl, 1989b, p. 24). Nessa perspectiva, torna-se compreensível que ao sair da reclusão, Frankl (2010) apregoa que quem sofreu injustiça não teria o direito de cometer injustiça.

Considera-se que tanto a vivência de Frankl (1989a) quanto a sua visão teórica são complementares, ou seja, constituem dois momentos distintos que resultam na visão de homem e de mundo. A Logoterapia e Análise Existencial se opõe a concepção reducionista, aquela em que o ser humano é completamente condicionado e sem qualquer possibilidade de escolha (pandeterminismo), pois não considera a pessoa como um joguete do destino. Como pode ser constatado por meio da análise da narrativa de Frankl, a pessoa é compreendida como um ser que responde às demandas do mundo. Na totalidade da obra de Frankl, o autor substitui a expressão "nada mais que", típica do reducionismo, por "mais que", o que resulta em uma compreensão de homem como um ser que é sempre "mais que" as suas condições internas e externas.

A estada de Frankl nos campos de concentração proporcionou a validação vivencial dos princípios que esse autor adota em sua visão antropológica, ressaltando, sobretudo, a "liberdade da vontade" e a "vontade de sentido". De forma geral, a técnica estatística textual aqui aplicada permitiu o mapeamento do mundo lexical da primeira parte da obra Em busca de Sentido, o que permitiu revelar a estrutura da sua narrativa. Essa análise, realizada por meio do ALCESTE, identificou três classes: por um lado, a classe 1, Facticidade dos prisioneiros, por outro as classes 2 e 3, Posicionamento psicoexistencial, corroborando a concepção desse autor segundo a qual o ser humano poderia se posicionar perante as condições psicossociais, escolhendo sua forma de ser-no-mundo por meio de sua dimensão noológica. Assim, considerou-se relevante analisar esse corpus tendo em vista que o mesmo desvela a essência do pensamento originário do autor em tela, tornando tangíveis os conceitos teóricos e filosóficos dessa abordagem. 


\section{Referências}

Caldas, M. T., \& Calheiros, M. E. (2012). O homem humanus à luz da verdade do ser e do sentido da vida: $O$ pensamento de Martin Heidegger e de Viktor Frankl acerca da humanitas. Revista Logos e Existência, 1, 88-99.

Dilthey, W. (1989) Introduction to the Human Sciences. Princeton, NJ: Princeton University Press.

Frankl, V. E. (1978). Fundamentos antropológicos da psicoterapia. Rio de Janeiro: Zahar Editores (Original publicado em 1975).

Frankl, V. E. (1989a). Psicoterapia e sentido da vida. São Paulo: Quadrantes (Original publicado em 1946).

Frankl, V. E. (1989b). Um sentido para a vida: Psicoterapia e humanismo. Aparecida, SP: Editora Santuário. (Original publicado em 1978).

Frankl, V. E. (1990). Logoterapia y análisis existencial. Barcelona: Editorial Herder. (Original publicado em 1967).

Frankl, V. E. (2006). Lo que no está escrito en mis libros: memorias. Buenos Aires: San Pablo. (Original publicado em 1995).

Frankl, V. E. (2010) Em busca de sentido: Um psicólogo no campo de concentração. São Leopoldo: Sinodal; Petrópolis: Vozes. (Original publicado em 1946).

Frankl, V. E. (2011). A vontade de sentido: Fundamentos e aplicações da logoterapia. São Paulo: Paulus. (Original publicado em 1969).

Garcia Pintos, C. (2007). Un hombre llamado Viktor. Buenos Aires: San Pablo.

Kronberger, N., \& Wagner, W. (2002). Palavras-chave em contexto: análise estatística de textos. Em M. W. Bauer, \& G. Gaskell (Orgs.), Pesquisa qualitativa com texto, imagem e som: um manual prático (pp. 461-441). Petrópolis: Vozes.
Levi, P. (1990). Os afogados e os sobreviventes. Rio de Janeiro: Paz e Terra

Liddell, H. G., \& Scott, R. (1983). A greek-english lexicon. Oxford: Claredon Press.

Lukas, E. (1989). Logoterapia: a força desafiadora do espírito (J. de Sá Porto, Trad.). São Paulo: Edições Loyola; Santos: Leopoldianum Editora.

Herrera, L. G. P. (2007). Viktor Frankl: Comunicación y resistencia. Buenos Aires: San Pablo.

ONU (1948). Declaração Universal dos Direitos Humanos. Disponível em: http:/portal.mj.gov.br/sedh/ct/legis intern/ ddh_bib_inter_universal.htm.

Reinert, M. (1990). Alceste, une méthodologie d'analyse dês données textuelles et une application. Bulletin de Méthodologie, 26, 24-54.

Reinert, M. (1998). Alceste. Version 4.0 - Windows (Manual). Toulouse: Societé IMAGE.

Thiago Antonio Avellar de Aquino é Graduado em Psicologia pela Universidade Federal da Paraíba, Mestre e Doutor em Psicologia Social pela Universidade Federal da Paraíba (UFPB); Professor Adjunto da Universidade Federal da Paraíba no Departamento de Ciências das Religiões; Professor credenciado do Programa de Pós-Graduação em Ciências das Religióes; é líder do grupo Nous: Espiritualidade \& Sentido (CNPq). Endereço Institucional: Universidade Federal da Paraíba, Centro de Educação - Campus I. Cidade Universitária. 58059-900 - João Pessoa, PB - Brasil. Email: logosvitae@ig.com.br

Recebido em 15.10 .12

Primeira Decisão Editorial em 21.11.12

Aceito em 21.12.12 